\title{
Abnormal Amniotic Fluid Index and Perinatal Outcomes among Pregnant Women with Prolonged Pregnancy at a Tertiary Health Institution, North-Western Nigeria
}

\author{
Ibrahim U Augie, Adamu N Aisha, Nwobodo EI, Umar G Amina, Ladan A Ashiru, Zubairu S, Dr \\ Asma'u Adamu M
}

\begin{abstract}
Background: Amniotic fluid (AF) is a part of the fetal life support system. It aids in the development of fetal muscles, limbs, lungs and digestive system. Amniotic fluid in women with prolonged pregnancy may be normal, low (oligohydramnios) or high (polyhydramnios). The degree of reduced amniotic fluid is proportional to the severity of placental hypo-perfusion.Intra uterine growth restriction (IUGR), cord compression, musculoskeletal, pulmonary hypoplasia and intra-partum fetal distress as well as neonatal birth asphyxia are some of the complications of amniotic fluid abnormalities.Postdated pregnancy is not usually associated with Polyhydramnios, outcome is mainly due to the underline cause of the polyhydramnios.

Aims: To determine the relationship betweenabnormal amniotic fluid index and perinatal outcomes among women with prolonged pregnancy.

Method: This is a cross-sectional study that was conducted among 130 pregnant women with prolonged pregnanciesbetween 40 weeks 1 day and 43 weeks of gestational age at the antenatal clinic, antenatal ward, radiology department, labour ward and special care baby unit of UsmanuDanfodiyo University Teaching Hospital (UDUTH), Sokoto. It involved pregnant women with gestational ages between 40 week 1 day and 43 weeks. They had their amniotic fluid index (AFI) assessed. Their pregnancies were followed till delivery.
\end{abstract}

Ibrahim U Augie, FMCOG, FWACS, Consultant Obstetrician and Gynaecologist , Department of Obstetrics and Gynaecology, Federal Medical Centre, BirninKebbi, KebbiStste.

Adamu N Aisha, FWACS, Senior Lecturer, UDUS and Chief Consultant Obstetrician and Gynaecologist, Department of Obstetrics and Gynaecology, Federal Medical Centre, BirninKebbi, KebbiStste.

Nwobodo EI, FWACS, Professor ofObstetrics and Gynaecology andConsultant Obstetrician and Gynaecologist, Departmrent of Obstetrics and Gynaecology, UsmanuDanfodiyo University/Teaching Hospital, Sokoto, Nigeria

Umar G Amina, FWACS, Senior Lecturer, UDUS and Consultant Obstetrician and Gynaecolodist, Departmrent of Obstetrics and Gynaecology, UsmanuDanfodiyo University/Teaching Hospital, Sokoto, Nigeria

Ladan AAshiru, FWACS, Consultant Obstetrician and Gynaecologist Department of Obstetrics and Gynaecology, Federal Medical Centre, BirninKebbi, KebbiStste.

Zubairu S,FMCOG, FWACS, Consultant Obstetrician and Gynaecologist, Department of Obstetrics and Gynaecology, Federal Medical Centre, BirninKebbi, KebbiStste.

Dr Asma'uAdamu M, MBBS (Sokoto), FWACP (Paed).Senior Lecturer/Consultant Paediatrician ,Department of Paediatrics,UsmanuDanfodiyo University/Teaching Hospital,Sokoto, Sokoto State
Results: The result obtained was analyzed using Software Package for Social Science(SPSS) version 20. There was significant relationship between level of amniotic fluid index and mode of delivery, fetal distress, APGAR scores, special baby care unit admission and perinatal death. However, there was no association between level of amniotic fluid and fetal birth weight.

Conclusion: Oligohydramnios among women with prolong pregnancy is associated with poor perinatal outcome. Hence prolong pregnancy should be considered as a high risk pregnancy. Fetal surveillance is suggested be instituted among women with oligohydramnios in order to improve perinatal outcome.

Index Terms - Amniotic fluid index, prolong pregnancy, perinatal outcome.

\section{INTRODUCTION}

Highlight Amniotic fluid is a clear, slightly yellowish liquid that surrounds the fetus during pregnancy. It is contained in the amniotic sac. Amniotic fluid is the product of complex and dynamic fetal and placental physiologic processes ${ }^{1}$.Disruption of the fine balance may result in over-production or under-production of the fluid. Therefore, alterations in amniotic fluid volume serve as important markers of in-utero developmental defects as well as physiological responses to fetal hypoxemia and other metabolic disturbances such as maternal/fetal hyperglycemia. Both polyhydramnios and oligohydramnios may result from abnormal fetal or maternal conditions and, conversely, may be responsible for adverse perinatal outcomes ${ }^{1}$.Fetal urination is the major source of amniotic fluid after fetal kidney function begins at 10-12 weeks, while the fetal lung fluid is a minor contributor to amniotic fluid volume ${ }^{2}$.Amniotic fluid volume rises progressively during gestation until approximately 32 weeks of gestation. From 32 weeks to term the mean amniotic fluid volume is relatively constant at about $700-800 \mathrm{ml}$. After 40 weeks there is progressive decline in amniotic fluid volume; it averages about $400 \mathrm{ml}$ at 42 weeks. The volume changes during normal pregnancies occur from 8-43 weeks of gestation ${ }^{3}$.

The quantity of amniotic fluid in the third trimester of pregnancy is the result of contributions from fetal urine and the secretion of fetal lung liquid on the one hand, and the removal of fluid by fetal swallowing and resorption through the fetal membranes on the other hand ${ }^{4}$.The mechanisms responsible for the regulation of the amniotic fluid volume are 


\section{Abnormal Amniotic Fluid Index and Perinatal Outcomes among Pregnant Women with Prolonged Pregnancy at a Tertiary Health Institution, North-Western Nigeria}

unknown ${ }^{5}$.

Amniotic fluid plays a major role in fetal growth and development. It provides the fetus with a protective low resistance environment suitable for growth and development. It provides a cushion against the constricting confines of the gravid uterus, allowing the fetus room for movement and growth. It helps to maintain the fetal body temperature, homeostasis of fluid and prevents compression of the umbilical cord. In addition, its bacteriostatic action helps prevent infection of the intra-amniotic environment ${ }^{3}$.The abnormalities of the fluid volume may be an indirect sign of underlying disorder such as fetal hypoxia, neural tube defect, anencephaly, urogenital abnormality or gastrointestinal obstruction $^{6}$.It is often assumed that the features of post-term pregnancy are the result of placental insufficiency and growth delay $^{2}$. There are similarities between clinical features of intrauterine growth restriction (IUGR) occurring earlier in pregnancy and post-term pregnancy. In the growth-restricted fetus changes in the circulation occur, favoring the brain, adrenals, and coronary arteries at the expense of other organ systems such as the digestive system and renal tract, a phenomenon known as "brain sparing" or "redistribution". In the growth-restricted fetus the reduced perfusion of the fetal kidneys is deemed responsible for a reduction of fetal urine output and a subsequent reduction of the amniotic fluid volume ${ }^{1}$.

Modern Obstetrics is concerned with the health and well-being of both the mother and her unborn child. Quantification of amniotic fluid is also an important component of the biophysical profile in ultrasound evaluation of fetal well-being, especially in prolonged pregnancies ${ }^{7}$.Ultrasound scan being a non-invasive test, is ideal for application on a large scale and can be used frequently for repeat AFV determination in the case of suspected abnormalities. ${ }^{5}$ Links have been found between decreased amniotic fluid index and stillbirths, fetal anomaly, abnormal FHR tracings in labor, increase in cesarean section for fetal distress, and possibly fetal acidosis ${ }^{5}$.

Prevalence of prolonged pregnancy varies from one region to another and from centre to centre. In a study conducted by Chantry et $a l^{6}$, it is complicated in $0.5-10 \%$ in European and American pregnancies. A study from Libya by Ibrahim et $a l^{4}$, reported a prevalence of $8.4 \%$. While Ambreenet $a l^{8}$ and Garbaet $a l^{9}$ reported prevalence's of $7.3 \%$ and $13.1 \%$ in Palestine and Kano, Nigeria respectively.

\section{Oligohydramnios}

The mechanisms by which amniotic fluid volume decreases in prolonged pregnancies remain unknown. ${ }^{10}$ The incidence of oligohydramnios in an unselected population without membrane rupture ranges from $0.4 \%$ to $19 \%$, depending on the criteria used for the diagnosis and the study population ${ }^{10}$. The onset may be either acute or chronic. Acute onset is most commonly as a result of membrane rupture, whereas chronic oligohydramnios may reflect a structural abnormality of the fetal urinary tract or a pathophysiologic response to chronic or intermittent fetal hypoxemia. Risk factors for oligohydramnios include fetal growth restriction, post-term pregnancy and repetitive cord compression. Other causes include fetal anomalies such as renal anomaly (e.gmulticystic dysplastic kidneys, polycystic kidneys, renal-agenesis), posterior urethral valves, bilateral uretero-pelvic junction obstruction and use of non-steroidal anti-inflammatory medications ${ }^{7}$.

\section{Polyhydramnios}

Polyhydramnios, is an excessive volume of amniotic fluid relative to the gestational age. It may be acute or chronic. Acute polyhydramnios is usually a fulminant second-trimester process, with fluid accumulating rapidly over a period of a few days ${ }^{11}$. Chronic polyhydramnios has a more gradual onset and course, often presenting in the third trimester. Overall, it complicates about $0.2-1.6 \%$ of all pregnancies ${ }^{11}$.It may be due to uncontrolled diabetes mellitus, isoimmunization, chorioangioma, Twin-to-twin transfusion syndrome, esophageal atresia, duodenal or jejunal atresia, diaphragmatic hernia, omphalocele, gastroschisis, sacrococcygealteratoma, cervical teratoma, Down syndrome, trisomy 13 and 18 , Pena-Shokeir syndrome, multiple congenital anomalies, myotonia-dystrophica, Homozygous $\alpha$-thalassemia, fetomaternal hemorrhage, Vasopressin insufficiency, Rubella, syphilis, toxoplasmosis, parvovirus, Non-immune hydropsfetalis and fetal retro-peritoneal fibrosis.Polyhydramnios is not a well-known complication of prolonged pregnancy, as such data concerning perinatal outcomes of prolonged pregnancies complicated by polyhydramnios especially in this part of the world is very scarce. The increased perinatal morbidity and mortality associated with polyhydramnios are due to both an increase in congenital/genetic anomalies and preterm births. Perinatal mortality used to be about $100 \%$ with acute polyhydramnios however, with aggressive repetitive amniocentesis; survivors have been reported. ${ }^{12}$ Chronicpolyhydramnios tends to have a better prognosis, especially if idiopathic in origin. Perinatal mortality has ranged from $34 \%$ to $69 \%$ in older studies ${ }^{12}$.Polyhydramnios may also be complicated by malpresentation, placental abruption (due to rapid decompression of the uterus at the time of rupture of membranes), dysfunctional labor patterns, and postpartum hemorrhage as a result of uterine atony ${ }^{13}$.

\section{MATERIAL AND METHOD}

The study was a cross-sectional analytic study among 130 pregnant women whose pregnancies were prolonged between 40 weeks 1 day and 43 weeks of gestation. Who were planned for elective vaginal delivery and meet the inclusion criteria had their amniotic fluid index assessed by ultrasound. The patients' consents were sought for and obtained by explaining to them the objectives of the study and the benefits there in. Their demographic characteristics, relevant obstetric history as well as their delivery outcome were acquired.

The study participants were recruited via simple random sampling technique; in which woman who met the inclusion criteria and gave informed consent to participate in the study were randomized and selected via "YES" or "NO" balloting at the antenatal care clinic, pre-natal ward and labour ward. All pregnant women attending antenatal clinic who met the inclusion criteria were sensitized for the study and the study procedure was explained to them. A Radiology requests form to estimate amniotic fluid index was filled-in for each study 
participant.

The amniotic fluid index of the entire study participantwas assessed with ultrasound scan at no cost. Following gel application on the maternal abdomen, a curvilinear transducer was used and the uterus was divided into 4 quadrants using the maternal sagittal midline vertically. The transducer was kept parallel to the maternal sagittal plane and perpendicular to the maternal coronal plane. The deepest, vertical clear pocket of amniotic fluid that was devoid of fetal part or umbilical cord was visualized and the image was frozen. The ultrasound calipers were manipulated to measure the pocket in a strictly vertical direction. The process was repeated in each of the other 3 quadrants and the four pocket measurements were added-up to estimate the amniotic fluid index.

\section{Data Analysis}

Data analysis was done using Statistical Package for Social Sciences (SPSS) version 20. Chi square $\left(\chi^{2}\right)$ and Fisher's exact test were used to assess the association between the variables and $5 \%(P 0.05)$ level of significance to test the homogeneity of the groups with respect to the distribution of patients over different classes of characteristic of interest such as mode of delivery, delivery outcome, APGAR score, birth weight and early neonatal outcome. Chi-square and Ficher's exact test were used to determine the association between each dependent variable with independent variables and level of significance at $P$ value $<0.05$.

\section{Ethical clearance}

Ethical approval was obtained from the UsmanuDanfodiyo

Table 1: Socio-demographic characteristics of women with prolonged pregnancy
University Teaching Hospital's Research and Ethics Committee before the study was carried out with reference number as; UDUTH/HREC/2018/NO. 73 issued on $27^{\text {th }}$ June, 2019. A written informed consent was obtained from the participants before enrolling them into the study and potential participants were informed that participation is voluntary and that standard care would be provided to all women regardless of their decision to participate in the study or not.

\section{Study funding}

The study was funded by the researchers.

\section{Study limitations}

Difficulty in excluding underlying primary placental pathology as it may affect the amount amniotic fluid and perinatal outcome was a limitation to this study. Also lack of facilities for continuous intra-partum electronic fetal monitoring with cardio-tocography (CTG) to exclude other causes of fetal heart rate abnormality and subsequent fetal outcome was another limitation.

\section{RESULT}

One hundred and thirty participants were recruited for the study at antenatal care clinic, pre-natal and labour wards. There was no single case of loss to flow-up. The mean age of the study participants was $29.66 \pm 5.75$. Majorities $(57.7 \%)$ of the study participants were multipara and $20.0 \%$ were primigravida. This is shown in Table 1 below.

\section{Characteristics}

Frequency (n)

Percentage (\%)

\section{Age (years) \\ Less than 20 \\ 20 to 29 \\ 30 to 39 \\ 40 and above}

\section{6}

63

54

7
4.6

48.5

41.5

5.4

\section{Occupation \\ Unemployed \\ Civil servant \\ Self employed}

56

28

46
43.1

21.5

35.4

$\begin{array}{lcc}\text { Educational Status } & & 8.5 \\ \text { No formal education } & 11 & 7.7 \\ \text { Primary } & 10 & 40.0 \\ \text { Secondary } & 52 & 43.8 \\ \text { Tertiary } & 57 & \\ & & 20.0 \\ \text { Parity } & & 57.7 \\ \text { Primigravida } & 26 & 22.3 \\ \text { Multigravida } & 75 & 29\end{array}$

Of the 130 study participants, $14.6 \%$ (19) had oligihydramnios, $83.1 \%$ (108) had normal amniotic fluid index while $2.3 \%$ had polyhydramnios. This is shown in the figurre 1 


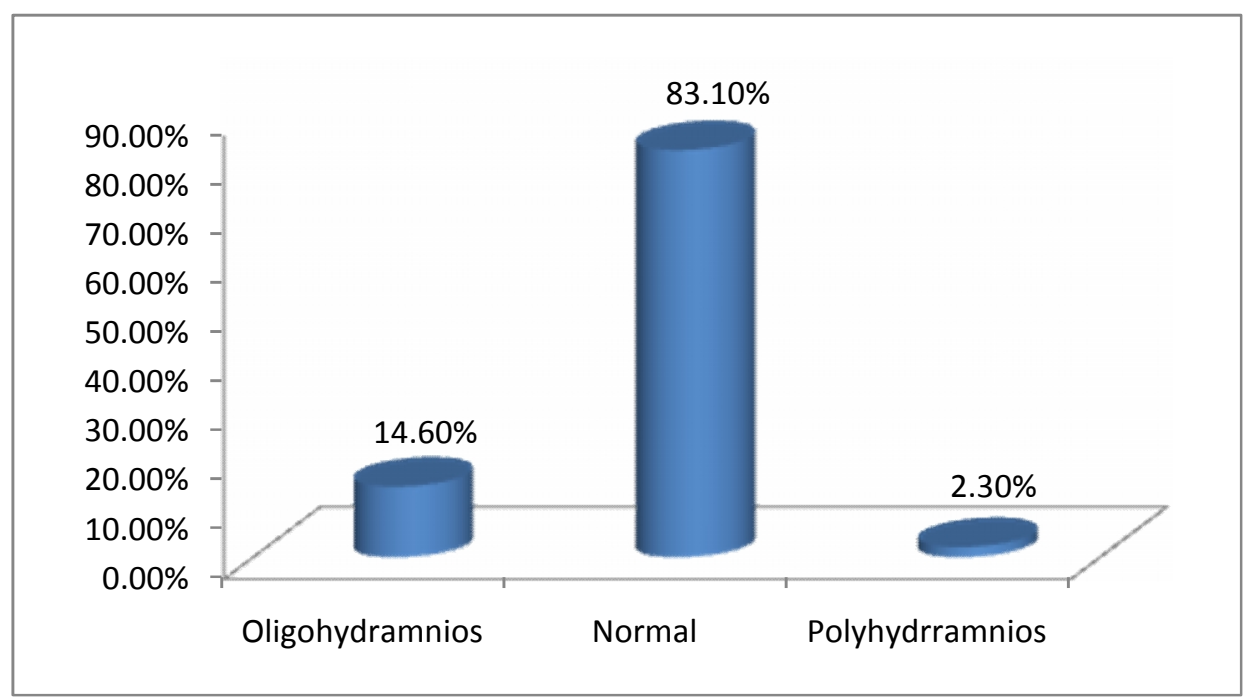

Figure 1: AFI distribution among women with prolonged pregnancy

Nineteen (14.5\%) of the study participants were delivered via Caesarean section, out of which 7 (36.8\%) were of oligohydramnios group while 12 (63.2\%) were those with normal AFI. Five (26.3\%) of the women who had Caesarean sections were purely due to oligohydramnios related indication while 14 (73.7\%) were due to other obstetrics indications. About $79 \%$ of the women had spontaneous vaginal delivery, $6.5 \%$ had instrumental vaginal delivery. This is shown in figure 2 below

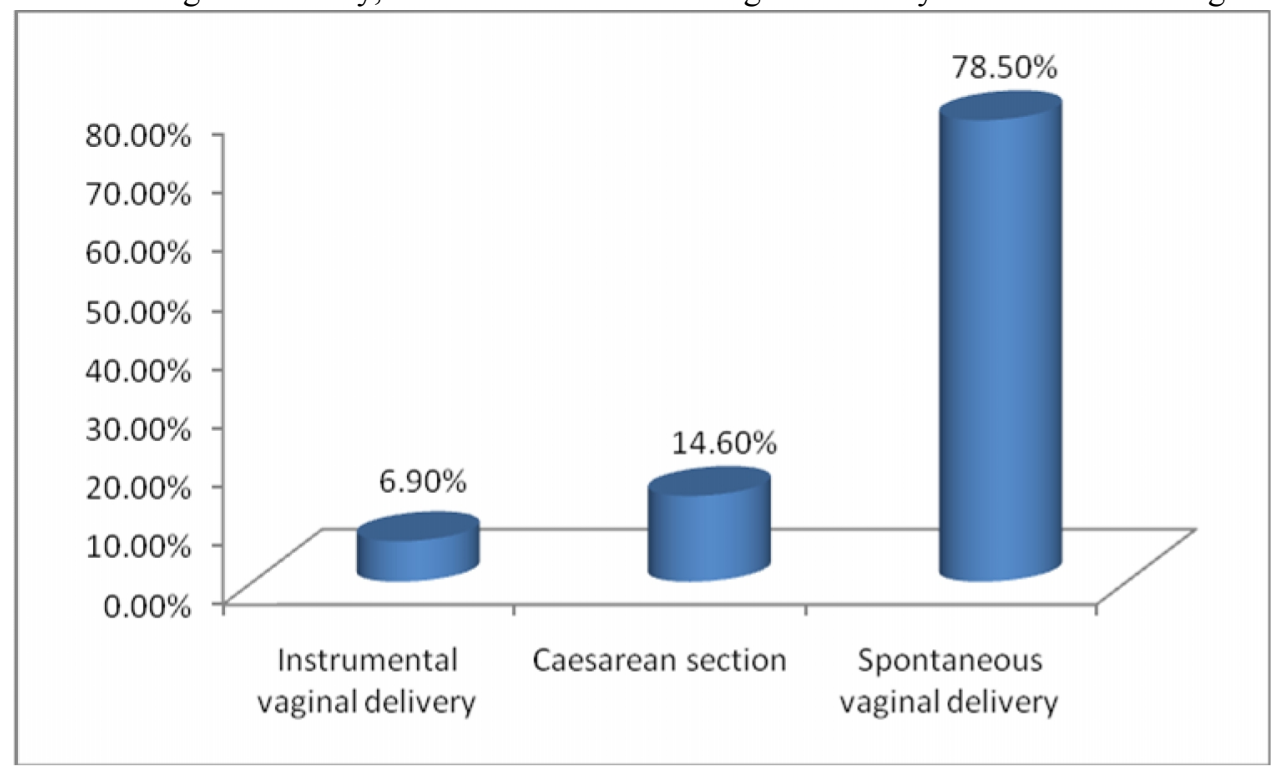

Figure 2: mode of delivery among women with prolonged pregnancy

Fourteen of the babies delivered by the study participant were admitted into the special baby care units (SCBU). Ten $(71.4 \%)$ of these were delivered by the women with oligohydramnios while $4(28.6 \%)$ were of normal AFI group. About $53 \%$ of the babies delivered to the women with oligohydramnios were admitted into the SCBU while only $3.7 \%$ of those delivered to the women with normal amniotic fluid index were admitted into the SCBU. Hence there was statistical significant relationship between oligohydramnios and admission into the special care baby unitwith $\mathrm{p}$ value $<0.001$.

There were $2(10.5 \%)$ still birth among women with oligohydromnious but there was no single $(0.0 \%)$ case of still born among women with normal AFI, with $p$ value $<0.001$ hence a significant association between AFI and prolonged pregnancy. There were $2(10.5 \%)$ neonatal death in the low AFI but there was no single neonatal death among normal AFI group. These are shown in figure 3 below 


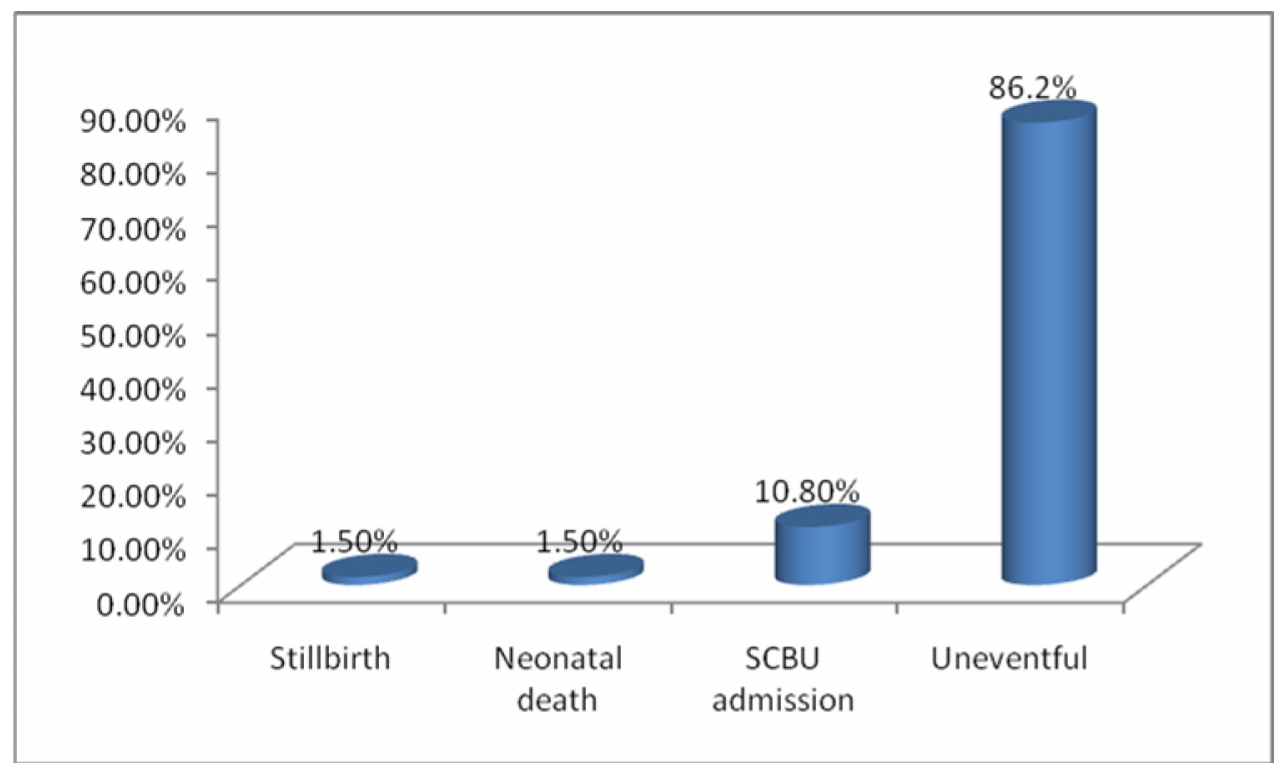

Figure 3. Early neonatal outcome among women with prolonged pregnancy

Seven ( $8.5 \%$ ) babies of the study population had birth asphyxia. About $11 \%$ of them were admitted into the special care baby unit (SCBU).

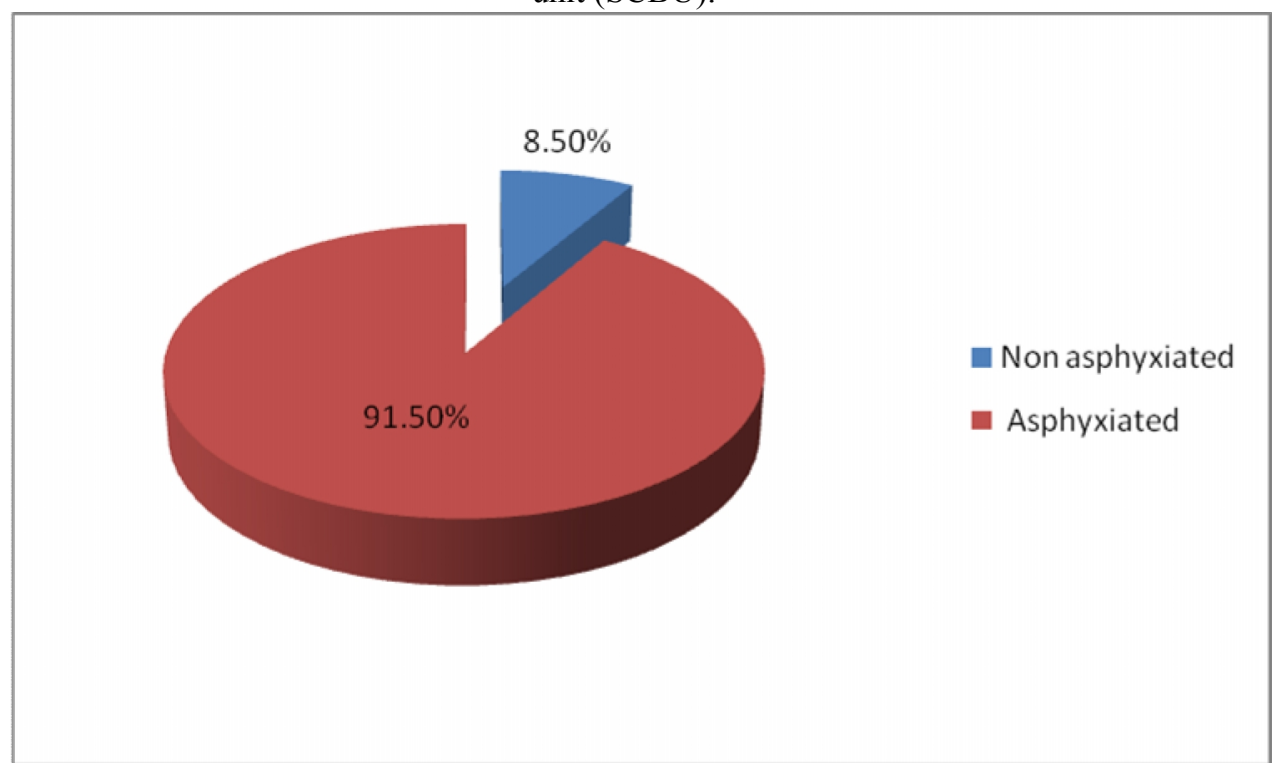

Figure 4: fetal birth asphyxia among women with prolonged pregnancy.

Five $(26.3 \%)$ of the women with oligohydramnios had Caesarean section while $13.0 \%$ of those with normal AFI had Caesarean section, with $\mathrm{p}$ value of 0.007 . Hence, there is statistically significant relationship between AFI and mode of delivery among women with prolonged pregnancy. It has also shown that $10.5 \%$ of the fetuses delivered by the women with oligohydramnios were of low birth weight. While $1.9 \%$ of fetus delivered to the women with normal AFI had low birth weight with $p$ value of 0.07 , thus there is no statistical significant relationship between level of amniotic fluid index and low birth weight. About $47 \%$ of the babies delivered to the women with oligohydromnious had birth asphyxia while $1.9 \%$ of those delivered to the women with normal AFI had birth asphyxia with $p$ value $<0.001$. Therefore there is statistically significant association between birth asphyxia and AFI.

There were $25(19.3 \%)$ case of fetal distress among the study participants, majority of them $18(72.0 \%)$ were those fetuses delivered by the women with oligohydramnios during labour, while 7 (28\%) of them were delivered by the women with normal AFI had fetal distress with $p$ value of $<0.001$. These are shown in table 2 below. 
Abnormal Amniotic Fluid Index and Perinatal Outcomes among Pregnant Women with Prolonged Pregnancy at a Tertiary Health Institution, North-Western Nigeria

Table 2; Association between AFI and neonatal outcomes among women with prolonged pregnancy

\begin{tabular}{|c|c|c|c|c|}
\hline Variables & $\begin{array}{l}\text { Oligohydramnio } \\
\text { s } \\
\text { n }(\%)\end{array}$ & $\begin{array}{l}\text { Normal } \\
\text { AFI } \\
\text { n (\%) }\end{array}$ & Statistical test & $P$ value \\
\hline $\begin{array}{l}\text { Mode of delivery } \\
\text { Spontaneous vaginal delivery } \\
\text { Instrumental delivery } \\
\text { Caesarean section }\end{array}$ & $\begin{array}{l}10(52.00) \\
4(21.1) \\
5(26.3)\end{array}$ & $\begin{array}{l}89(82.4) \\
5(4.6) \\
14(13.0)\end{array}$ & $\begin{aligned} & \text { Fisher's exact test } \\
= & 8.8\end{aligned}$ & 0.007 \\
\hline $\begin{array}{l}\text { Delivery outcome } \\
\text { Live birth } \\
\text { Still birth }\end{array}$ & $\begin{array}{l}17(89.5) \\
2(10.5)\end{array}$ & $\begin{array}{l}108(100.0) \\
0(0.0)\end{array}$ & $\chi^{2}=11.6$ & $<0.001$ \\
\hline $\begin{array}{l}\text { Birth weight } \\
\text { Low Birth Wright } \\
\text { Normal Birth Weight } \\
\text { Fetal Macrosomia } \\
\end{array}$ & $\begin{array}{l}2(10.5) \\
17(89.5) \\
0(0.0)\end{array}$ & $\begin{array}{l}2(1.9) \\
95(87.9) \\
11(10.2)\end{array}$ & $\begin{array}{l}\text { Fisher's exact test }= \\
7.8\end{array}$ & 0.072 \\
\hline $\begin{array}{l}5^{\text {th }} \text { minute APGAR score } \\
0-3 \\
4-7 \\
8-10\end{array}$ & $\begin{array}{l}4(21.1) \\
5(26.3) \\
10(52.6)\end{array}$ & $\begin{array}{l}0(0.0) \\
2(1.9) \\
106(98.1)\end{array}$ & $\begin{aligned} & \text { Fisher's exact test } \\
= & 29.6\end{aligned}$ & $<0.001$ \\
\hline $\begin{array}{l}\text { Early neonatal outcome } \\
\text { SCBU admission } \\
\text { Neonatal death } \\
\text { Uneventful }\end{array}$ & $\begin{array}{l}10(52.6) \\
2(10.5) \\
5(26.9)\end{array}$ & $\begin{array}{l}4(3.7) \\
0(0.0) \\
104(96.5)\end{array}$ & $\begin{array}{l}\text { Fisher's exact test }= \\
48.4\end{array}$ & $<0.001$ \\
\hline $\begin{array}{l}\text { Fetal distress } \\
\text { Yes } \\
\text { No }\end{array}$ & $\begin{array}{l}18(94.7) \\
1(5.3)\end{array}$ & $\begin{array}{l}7(6.5) \\
101(93.5)\end{array}$ & $\chi^{2}=79.6$ & $<0.001$ \\
\hline Total & & & & \\
\hline
\end{tabular}

distress (57.4 versus 38.7) in women with oligohydramnios compared to those with normal AFI. Though, their study was conducted in women between 34-41 weeks of gestation. Hence their study participants included women who had preterm delivery and preterm babies. And prematurity itself is a risk factor for fetal distress and consequently risk for Caesarean delivery. This finding was also similar to what was reported by Lalocatelliet al. ${ }^{15}$ However, in contrary, a case-control study conducted by Ibrahim et $\mathrm{al}^{9}$ in Mansurat, Egypt showed no statistical significant difference between women with oligihydramnios and normal AFI in terms of Caesarean delivery. Though their cases are similar to ours, but the control groups were recruited from gestational age of 34 weeks. Also in their study some women with indication for elective Caesarean delivery were included in their study. This could have affected the rate of Caesarean section in their study.

With regards to the birth weight, in this study, it was found that was no statistical significant relationship between low AFI and low birth weight as majority of the women with oligohydramnios had fetuses that weighed between 3001 to $3500 \mathrm{~g}$. And this is similar between the two groups. This finding is comparable to what was found by Sultana et $a l^{16}$, whom in their study observed that the difference in low birth weight was not significant between the two groups of AFI ( $p$ value 0.4 ). This similarity may probably be due to similarity in the study methodology between our study and theirs'. However, our finding was contrary to what was found by Moriset $a l^{17}$, Bhagatet $a l^{14}$, Rutherford et $\mathrm{al}^{17}$ and Amanyet $a l^{18}$. Although the studies by Moriset $a l^{15}$ and Rutherford et 
$a l^{17}$ were both conducted among women with prolonged pregnancy but the studies by Bhagatet al ${ }^{14}$ and Amanyet al ${ }^{18}$ included women with preterm pregnancy hence, it could have been the reason for the higher low birth weight in their studies.

With regards to the delivery outcome, our study found that there was a statistical significant association between oligohydramnios and perinatal death, as $10.5 \%$ of the fetuses delivered by the women with oligohydramnios were still birth. This finding was similar to what was reported by Panda et $a l^{20}$ and Vermaet $a l^{21}$ who found a significant association between low AFI and perinatal mortality (with $p$ value of $<0.001$ and 0.047 respectively). However, it was inconsistent with what was reported by Bhagatet al ${ }^{14}$, Paiet $a l^{22}$ and Amanyet $a l^{19}$.

In the present study we found a statistical significant difference between oligohydramnios and normal AFI groups in terms of SCBU admission with $p$ value of $<0.001$. This high value could have probably been to the lack of facility for continued intra-partum electronic fetal monitoring. This finding is similar to the study conducted by Vermaet $a l^{21}$ ( $p$ value 0.037$)$. Though continued intra-partum electronic fetal monitoring was employed in their study however, their study was conducted among women at $\geq 34$ weeks of gestational age hence included preterm fetuses and prematurity on its own constituted a risk for admission into special baby care unit (SCBU). Bhagatet $\mathrm{al}^{14}$ (though their study was also conducted among women of same gestational age as Vermaet $a l^{2 l}$, and both were case-control studies) but found no statistical significant difference in SCBU admission between women with oligohydramnios and those with normal AFI(reported $92 \%$ versus $71.4 \%$ respectively between the two groups). This could be due to the smaller sample size of their study.

Also in this study, it was found that babies delivered to women with oligohydramnios had more birth asphyxia compared to those delivered to women of normal AFI group with $p$ value of $<0.001$. Hence there was statistical significant association between oligohydramnios and low $5^{\text {th }}$ minute APGAR score. This is in consistent with high rate of fetal distress recorded in this study which could be related to the low $5^{\text {th }}$ minute APGAR score. This finding is consistent with what was reported by Ahmed et $a l^{23}$. However, it was contrary with what was reported by Vermaet $a l^{20}$ who found no significant association between low AFI and $5^{\text {th }}$ minute APGAR (0.05). Similarly Locatelliet $a 1^{15}$ and Bhagatet $a l^{14}$ found no statistical difference in the APGAR score at $5^{\text {th }}$ minutes between the two groups. However, in all their studies there was continued electronic fetal monitoring hence fetal heart rates abnormalities that were due to other causes were excluded and specific interventions were instituted.This intervention could be the reason for the less asphyxiated babies recorded in their studies. This intervention was not done in this our study hence could have been the reason for the higher birth asphyxia recorded in our study.

There was higher fetal distress among women with oligohydramnious among women with oligohydramnios compared to women with normal AFI (94.7\% vsersus $6.5 \%$. This is similar to what was reported byLocatelliet $a l^{15}$,Vermaet $a l^{21}$ and Paiet $a l^{22}$.

\section{CONCLUSION}

The findings in this study showed that oligohydramnios $(\mathrm{AFI}<5 \mathrm{~cm})$ was significantly associated with mode of delivery, delivery outcome, APGAR score and early neonatal outcome. However, there was no significant association between oligohydramnios and fetal birth weight.

\section{RECOMMENDATION}

Facilities for continues intra-partum electronic fetal monitoring. Also there is need to provide adequate facilities in all tertiary centers for women with prolonged pregnancy for adequate intrapartum monitoring (especially those with oligohydramnios) as it constitutes a high risk pregnancy.

\section{COMFLICT OF INTEREST}

We declare no conflict of interest.

\section{REFERENCES}

[1] Lord M, Bhimje SS. Amniotic Fluid Index .StatPearls Publishing; 2018 .

[2] Micheal GR. Physiology of amniotic fluid volume regulation; Uptodate. Wolters Kluwer. 2017.

[3] Ounpraseuth ST, Magann EF, Spenes HT. Normal Amniotic Fluid Volume Across Gestation: comparism of statistical approach in 119 normal fluid volume. J ObstetGynaecol Res. 2017; 4: 1122.

[4] Ibrahim AL, Bashir DE, Muftah AS. Prolonged Pregnancy: Prevalance, cause and outcomes.

[5] Manning FA. Antepartum fetal testing: a critical appraisal. CurrOpinObstet Gynecol. 2009;21(4):348-352.

[6] Chantry AA, Lopez E. Fetal and Neonatal Complications Related to Prolonged Pregnancy.

GynaecolObstetBiolReprod.2011;40(8):717-725.

[7] Chamberlain PF, Manning FA, Morrison I, et al. The relationship of marginal and decreased amniotic fluid volumes to perinatal outcome.Am J Obstet Gynecol. 1984;150(3):245-249.

[8] Ambreen NH, Saadat A and Zaiba S. induction of Labour in Postdate pregnant Women. J CollPhysSurg Palestine. 2012: 22(10); 144-147.

[9] Garba I, Muhammed AS, Muhammed Z, Galadanci HS, Ayyuba R, Abubakar S, Induction to delivery interval using Foley's catheter plus oxytocin and vaginal misoprostol. A comparative study at Aminu Kano Teaching Hospital, Kano Nigeria.Ann Afr Med. 2016;15:14-19.

[10] Cheung CY, Anderson DF, Brace RA. Aquaporins in Ovine Amnion: Responses to altered Amniotic Fluid Volume \& Intra-membranous absorption rate. Physiol Rep. 2016; 4.

[11] Hamza A, Harr D, Solomayer EF and Meyberg-Solomeyer G. Polyhydramnios: causes, diagnosis and therapy. GuburtshilfeFrauenheilkunde. 2013; 73(12): 1241-1246.

[12] Denehy TR, Hollander DI, Dembner A.: Acute polyhydramnios. Int J Gynecol Obstet. 1989; 28: 181 .

[13] Panting-Kemp A, Nguyen T, Chang E, Quillen E, Castro L. Idiopathic polyhydramnios and perinatal outcome. Am J Obstet Gynecol.1999; 181(1): 73-76.

[14] Bhagat M and Chawla I. Correlation of Amniotic Fluid Index and Perinatal Outcomes.J ObstetGynaecol India. 2014 Feb; 64(1): 32-35.

[15] Locatelli A, Zagarell A, Toso L, Assi F, Ghidini A, Biffi A. Serial assessment of amniotic fluid index in uncomplicated term pregnancies: prognostic value of amniotic fluid reduction. J Matern Fetal Neonatal Med 2004; 15: 233-236.

[16] Sultana S, Akbar Khan MN, KhanumAkhtar KA, Aslam M. Low amniotic fluid index in high-risk pregnancy and poor apgar score at birth. J coll physician surgpak. 2008; 18(10): 630-4.

[17] Morris JM, Thompson K, Smithey J et al. The usefulness of ultrasound assessment ofamniotic fluid in predicting adverse outcome in prolonged pregnancy: a prospective blinded observational study. Brit $\mathrm{J}$ ObstetGynaecol2003;110: 989-994.

[18] Rutherford SE, Phelan JP, Smith CV, et al. The four quadrant assessment of amniotic fluid volume: an adjunct to antepartum fetal heart rate testing. Obstet Gynecol. 1987;70(3): 353-356.

[19] Amany HGN. IOSR J NursHealt Sci. 2015; 4(5):65-75. 
Abnormal Amniotic Fluid Index and Perinatal Outcomes among Pregnant Women with Prolonged Pregnancy at a Tertiary Health Institution, North-Western Nigeria

[20] Panda S, Javalakshmi M, ShashiKumari G, Mahalashmi G, Saijan Y and Anusha V. Oligohydromnious and Perinatal Outcomes. J ObstGynaecol India. 2017;67(20):104-108.

[21] Verma M, Gupta S, AhujaMV,Pratap P. Relationship of decreased amniotic fluidand perinatal outcome: a comparative study. Int JRes Med Sci 2016;4:4093-6.

[22] Pai M.M, Muralidhar V.P, Roopa P.S. Is low amniotic fluid index an indicator of fetal distress and hence delivery?.IntJ ReprodContraceptObstet Gynecol. 2016; 5(3): 656-658.

[23] Ahmad H. and Munim, S. Isolated oligohydramnios is not an indicator for adverse perinatal outcome. J Pakistan Med Assoc. 2009; 59(10): 691-694. 